\title{
Nonce-loan judgments and impossible-nativization effects in Japanese
}

\author{
Jennifer L. Smith \& Yuka Tashiro*
}

\begin{abstract}
The core-periphery structure of the Japanese lexicon is well documented (e.g., Ito \& Mester 1995ab, 1999), but there is some controversy as to whether it is synchronically productive. Productive core-periphery structure should show synchronic evidence for a HIERARCHY OF FOREIGNNESS (Kiparsky 1973) among non-native phonological structures, and should give rise to IMPOSSIBLENATIVIZATION EFFECTS (Ito \& Mester 1999, 2001) — speakers should reject a nonce loanword that nativizes a 'less-foreign' structure while preserving a 'more-foreign' one. We carried out an experiment to collect nonce-loan nativization judgments from speakers of Japanese in order to test these claims. We found, first, that participants have a hierarchy of foreignness that is approximately like the predicted one, but differs in the relative markedness of singleton [p] and sequences of nasal+voiceless obstruent; we also found some interspeaker variation in the hierarchy. Second, while most participants showed nativization preferences that look like impossiblenativization effects, not all participants had a consistent hierarchy of preferences across all constraint pairs. These results have implications both for the phonological analysis of existing stratum-specific alternations in Japanese and for theoretical approaches to loanword phonology.
\end{abstract}

Keywords. loanword phonology; lexical strata; core-periphery structure; impossiblenativization effects; experimental phonology; Japanese phonology

1. Introduction. The Japanese lexicon is rich in loanwords, and is often described as having a core-periphery structure (Ito \& Mester 1995ab, 1999) that reflects what Kiparsky (1973) calls a hierarchy of foreignness. However, it is still controversial whether this core-periphery structure should be considered a productive part of the synchronic phonology.

Ito \& Mester $(1999,2001)$ argue that, if a hierarchy of foreignness that creates a coreperiphery structure is active in the grammar, speakers will show impossible-nativization effects. That is, speakers should show a consistent preference for nativizing one particular phonological property as opposed to another. Ito \& Mester $(1999,2001)$ discuss impossible-nativization effects in potential variants of existing Japanese loanwords that are consistent with a synchronic status for core-periphery structure. However, their discussion is based on judgments provided by a small number of speakers who are not necessarily linguistically naive.

In order to explore further the synchronic status of core-periphery structure in Japanese phonology, we collected nonce-loan nativization judgements from native Japanese speakers. Our results show that Japanese speakers have a hierarchy of foreignness that is approximately like the hierarchy predicted from existing alternations that are specific to particular lexical strata in Japanese. Moreover, most participants showed nativization preferences that look like impossible-

\footnotetext{
* Many thanks to the Institute for the Arts and Humanities at UNC Chapel Hill for support, to Chris Wiesen at the Odum Institute at UNC Chapel Hill for statistical consulting, to Shigeto Kawahara and Masayuki Tashiro for experiment materials and recruiting, and, for helpful comments and discussion on earlier versions of this work, to audience members at OCP15, LSA 2019, and the P-side discussion group at UNC Chapel Hill. Authors: Jennifer L. Smith, University of North Carolina at Chapel Hill (jlsmith@email.unc.edu) \& Yuka Tashiro, University of North Carolina at Chapel Hill (yuka.m.tashiro@gmail.com).
} 
nativization effects. However, not all participants had a consistent hierarchy of nativization preferences across all constraint pairs, a result that is unexpected if core-periphery structure is productive.

We begin this paper with background discussion of impossible-nativization effects and Japanese phonology $(\S 2)$. We then describe the nonce-loan nativization experiment $(\S 3)$ and report and discuss our findings $(\S 4)$. Finally, we consider some theoretical implications and questions for further investigation $(\S 5)$.

2. Core-periphery structure and impossible nativization effects. When loanwords are adapted from a source language to a borrowing language, their phonological properties may be modified so that they meet the phonotactic requirements of the borrowing language, but sometimes, some of the original 'non-native' phonological properties are maintained. This process may yield a stratified lexicon, with lexical subclasses that exhibit distinct phonological characteristics (Chomsky \& Halle 1968; Postal 1968; Saciuk 1969; Kiparsky 1973; Holden 1976).

These distinct lexical subclasses are not necessarily independent, parallel subsets. Kiparsky (1973) argues that loanwords in a language can show a hierarchy of foreignness: some borrowed forms maintain more non-native characteristics than others. This may happen when some of the phonological properties that were avoided in the native stratum or other older strata have gradually become more accepted and are preserved in newer strata. This leads to what Ito \& Mester (1995ab, 1999) call core-periphery structure, in which a stratified lexicon shows an implicational hierarchy of phonological properties: if a loanword has nativized phonological property A, then it must also have nativized phonological property B, but not vice versa. Ito \& Mester (1995ab, 1999) argue that the phonological lexicon of the Japanese language is organized in a core-periphery structure, exhibiting a implicational hierarchy of markedness constraints of just this kind.

Figure 1 shows a schematic example of a lexicon with a core-periphery structure. The etymologically oldest stratum, here $\mathrm{X}$, is the core stratum, in which the maximum number of markedness constraints are enforced. As one moves through more peripheral strata, or etymologically younger strata, here $\mathrm{Y}$ and $\mathrm{Z}$, these once-enforced markedness constraints gradually become dominated.

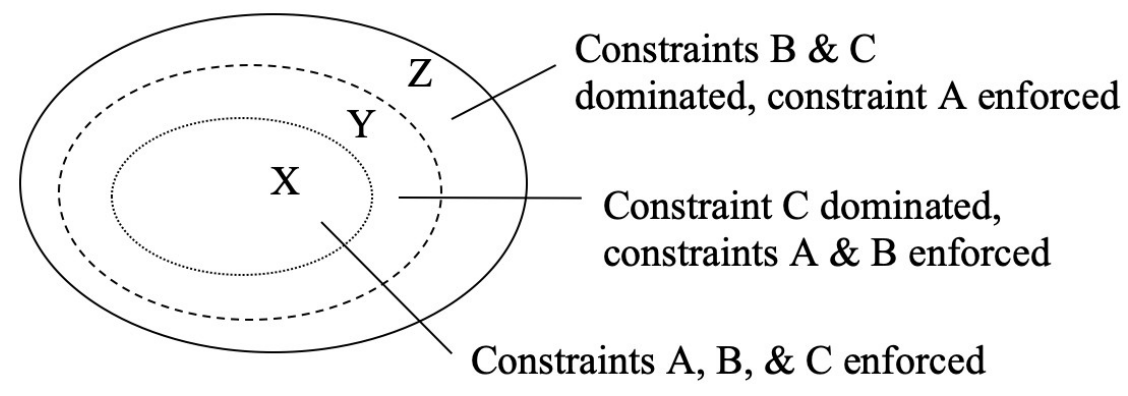

Figure 1: A lexicon with a core-periphery structure

Ito \& Mester (1999) propose a formal optimality-theoretic analysis to account for this kind of lexical subset structure. The implicational relations among 'non-native' phonological properties are modeled with markedness constraints that form a single hierarchy, where lowerranked markedness constraints model the weaker dispreference for 'less-foreign' properties, and higher-ranked markedness constraints model the stronger dispreference for 'more-foreign' 
properties. Stratum-specific faithfulness constraints are used to model stratum-specific behavior, with higher-ranked faithfulness constraints corresponding to more-peripheral strata - in which, therefore, the lower-ranked markedness constraints come to be dominated. The precise details of the nature of faithfulness and markedness constraint interaction for modeling lexical strata are still under debate; see, for example, Inkelas \& Zoll (2007) and Hsu \& Jesney $(2017,2018)$ for alternative approaches.

Our focus in this paper is on whether this kind of core-periphery structure should be considered a productive part of the synchronic phonology at all, or whether it is just a historical record of linguistic change. As C. Rice (2006) argues, diachronic factors can yield this kind of structure even in a language where the synchronic phonology makes no distinctions among lexical strata. One familiar source of evidence that a particular language has a synchronically productive core-periphery phonology is the existence of active, stratum-specific phonological alternations (Ito \& Mester 1999).

However, there is an additional source of evidence for productive core-periphery structure that has not been as thoroughly discussed: impossible-nativization effects (Ito \& Mester 1999, 2001). If the productive phonological grammar includes the markedness constraint hierarchy NoA » NoB, then a loanword that nativizes B but not A should be impossible, so a speaker who is given the choice of nativizing only A or only B should consistently prefer to nativize A. This consistent preference for one nativization over another is an impossible-nativization effect.

Ito \& Mester $(1999,2001)$ discuss impossible-nativization effects in Japanese loanwords that support the existence of synchronic core-periphery structure. However, their discussion is not based on empirical data provided by linguistically naive native speakers. To our knowledge, there is no prior work reporting results from experiments that test for productive impossiblenativization effects in novel forms with native Japanese speakers. Our study therefore empirically investigates impossible-nativization effects in Japanese.

The Japanese language is rich in loanwords, and the stratified structure of its lexicon has been well established by many researchers (e.g., McCawley 1968; Vance 1987; Ito \& Mester 1995ab, 1999; Irwin 2011). There are four strata that are most relevant to our study: the Native, Sino-Japanese, Assimilated Foreign, and Unassimilated Foreign strata. These strata approximately correspond to etymological classes, but crucially, they behave differently with respect to the markedness constraints shown below (adapted from Ito \& Mester 1999).

(1) Markedness constraints that distinguish lexical strata in Japanese

NoNT: $\quad$ Assign one $*$ for every nasal+voiceless obstruent sequence (Hayes 1999; Pater 2001)

NoP: $\quad$ Assign one * for every singleton $[\mathrm{p}]$

NoDD: $\quad$ Assign one $*$ for every voiced geminate obstruent

NoTI: $\quad$ Assign one * for every sequence of coronal plosive+[i]

NoSI: $\quad$ Assign one $*$ for every sequence of coronal fricative+[i]

In the Native stratum, all of these five constraints are actively enforced. However, in the Sino-Japanese stratum, NoNT is not enforced. In the Assimilated Foreign stratum, neither NoNT nor NoP is enforced. In the Unassimilated Foreign stratum, NoNT, NoP, NoDD, and NoTI have all ceased to be enforced. (The enforcement of these constraints is shown by active alternations; see Ito \& Mester 1999 for examples.) 
This situation appears to be an instance of the abstract core-periphery structure shown in Figure 1. That is, evidence from existing stratum-specific alternations in Japanese supports a markedness constraint hierarchy as shown in (2).

(2) Predicted hierarchy of foreignness

NoSI »\{NoTI, NoDD $\} »$ NoP » NoNT

3. Nonce-loan nativization experiment. Our study was designed to see whether the predicted hierarchy of foreignness in (2) is attested, and leads to productive impossible-nativization effects, in the phonological system of speakers of Japanese. Such effects would demonstrate that coreperiphery structure is a productive part of the synchronic phonological grammar.

The experiment was a two-alternative forced-choice questionnaire study. The stimuli consisted of pseudo-English nonce words, each presented along with a pair of nativization options. Participants were asked to choose the option that was most natural as a Japanese form of each "English" word. Because of the forced-choice structure of the experiment, participants were required to select a response that nativized one of the properties in question while preserving the other. We chose this procedure because it would allow us to see which constraint is satisfied at the expense of the other; nativizations that tolerate both, or neither, of the non-native structures under consideration are logically possible but not informative.

We tested all pairwise comparisons among the five markedness constraints in (2), which yields ten constraint pairs. For each constraint pair, we created four English-like nonce words that include the phonological properties with which each constraint in the pair is concerned. The order of the phonological properties in the nonce words in each set was counterbalanced. Every English nonce word was given two Japanese nativization options, each of which nativized exactly one of the two phonological properties in question. Our methodology is based on that of the nonce-loan nativization experiment conducted by Pinta (2013) with speakers of Guarani, except that we tested a greater number of constraint pairs and included audio stimuli.

Example (3) shows the English nonce words and corresponding Japanese nativization options that tested the relative ranking of NoSI and NoP. (Epenthesis and vowel nativization patterns in the response options are based on existing loanwords in Japanese.)

(3) Nonce words and nativization options

\begin{tabular}{|c|c|c|}
\hline English nonce word & $\begin{array}{l}\text { Nativize /si/ to [6i] } \\
\text { (satisfies only NoSI) }\end{array}$ & $\begin{array}{l}\text { Nativize /p/ to [h] } \\
\text { (satisfies only NoP) }\end{array}$ \\
\hline pimsil [pimsil] & [pimusiru] & [himusisiru] \\
\hline polsift [pols $\underline{\text { Ift }}$ ] & [porusiфuto] & [horusisiфuto] \\
\hline sifpem [sIfpem] & [6iфupemu] & [siфuhemu] \\
\hline silpesk [sIlpesk] & [6irupesukw] & [isuheswkw] \\
\hline
\end{tabular}

The participants were also given three practice items at the beginning of the experiment session. Unlike the stimuli above, each practice item was a real English word (e.g., Twitter [twIr.] ) that has two controversial adaptation forms in Japanese (e.g., [tsuitta:] and [tuitta:]), and each practice item involved only one markedness constraint. All the instructions were given in Japanese. All the stimuli were presented as both audio and orthography, with the nonce words and their nativization options given in standard English and Japanese katakana orthography 
respectively; see the Appendix for an example screenshot from the experiment. Participants could replay the audio as many times as they needed to.

There were 40 participants, recruited online via email and social media. All participants were self-reported native speakers of Japanese, raised in Japan, and over the age of 18 . There were 26 female and 13 male participants, and 1 participant who did not report gender. Year of birth ranged from 1997 (age 20) to 1959 (age 58), with a median of 1985 (age 32). As for education level, there were 1 high school graduate, 2 technical school/junior college graduates, 7 four-year university students, 17 participants with a four-year university degree, 1 masters program student, 5 participants with a masters degree, 3 doctoral students, and 4 participants with a doctoral degree.

4. Results and discussion. To recapitulate, our two main predictions are as follows. First, if the hierarchy of foreignness proposed by Ito \& Mester (1995ab, 1999) and supported by attested stratum- specific alternations is productive, then the responses to each pairwise comparison should match the hierarchy in (4), repeated from (2) above.

(4) Predicted hierarchy of foreignness

NoSI » $\{$ NoTI, NoDD $\} »$ NoP » NoNT

Second, if core-periphery structure is a productive part of the synchronic phonology, then each participant should have some consistent hierarchy of preferences, that is, should show impossible-nativization effects. This hierarchy, however, may not be the same for all participants.

4.1. RESULTS: HIERARCHY OF FOREIGNNESS. In order to see whether the predicted hierarchy in (4) above is supported by our nativization results, we determined, for each constraint pair, how many participants ranked that pair in accordance with (4) how many times. These results are presented in Figure 2, where blue bars indicate the number of participants with $4 / 4$ or 3/4 rankings as predicted for a given constraint pair, red bars indicate the number of participants with $0 / 4$ or $1 / 4$ rankings as predicted, and gray bars indicate a $2 / 4$ tied result. The predicted hierarchy has NoTI and NoDD ranked equally, so for this constraint pair, we arbitrarily chose blue to represent participants consistent with NoTI » NoDD (4/4 or 3/4 times NoTI » NoDD) and red for participants consistent with NoDD » NoTI (0/4 or 1/4 times NoTI » NoDD).

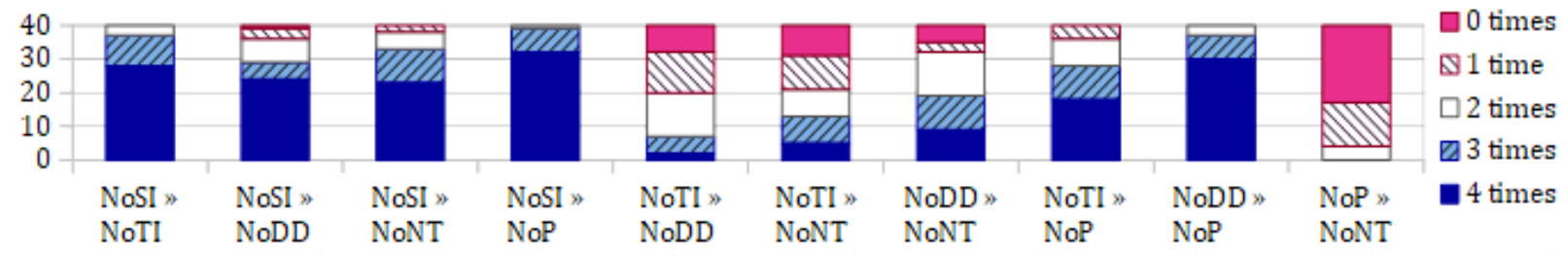

Figure 2: For each constraint pair, the number of participants showing the predicted ranking 0-4 times

As Figure 2 shows, there are several points of agreement between our results and the predicted hierarchy in (4). The leftmost four bars confirm that NoSI is very highly prioritized, dominating all of the other constraints for the majority of participants. Also as expected, NoSI, NoTI, and NoDD are all higher than NoP. Finally, consistent with the lack of a predicted rank between NoTI and NoDD, these two constraints varied both within and between participants. That is, there is a relatively high proportion of participants who ranked these two constraints in 
each order twice (gray), and we see both participants favoring NoTI » NoDD (blue) as well as those favoring NoDD » NoTI (red).

Our results also show points of difference from the predicted hierarchy. The rightmost bar in Figure 2 shows that no participant, out of 40, prioritized NoP over NoNT. NoNT also showed about as much variability with both NoTI and NoDD as NoNT and NoDD showed with one another. In other words, NoP was ranked lower than expected, and NoNT higher. The "hierarchy of foreignness" supported by our results pooled across subjects is thus as shown in (5).

(5) Hierarchy of foreignness supported by pooled results

NoSI » $\{$ NoTI, NoDD, NoNT $\} »$ NoP

4.2. DISCUSSION: HIERARCHY OF FOREIGNNESS. The consistently high rank for NoSI in our results matches its position in the predicted hierarchy. There is, in fact, almost no evidence in existing loans that this constraint is ever violated. Irwin (2011:84) notes that "perhaps the only examples" of [si] (or [zi]) in loanwords are very careful productions of the names of the letters (English) $C$ as [si:] and (North American English) $Z$ as [zi:], and the interesting case of English season [si:zən], which is typically [6i:zun] but has a variant [si:zun] that is used exclusively by sports commentators. Ito \& Mester (1999:77) likewise assert that NoSI is obeyed in "practically all recent loans."

On the other hand, the low rank for NoP is surprising. One might expect this constraint to be ranked higher, because there are many alternations between [h] and [p] (and sometimes [b] in voicing contexts) in Native and SJ forms, with [p] appearing in these strata only as part of a geminate ([pp]) or place-linked ([mp]) structure; see an example in (6).

(6) Example of an alternating $[\mathrm{h}] \sim[\mathrm{p}] \sim[\mathrm{b}]$ segment
a. [nihai] '2 cups' (SJ)
([h] after vowel)
b. [ippai] ' 1 cup' (geminate $[\mathrm{p}]$ allowed)
c. [sambai] ' 3 cups' (postnasal voicing)

In traditional generative phonology, these alternating $[\mathrm{h}] \sim[\mathrm{p}](\sim[\mathrm{b}])$ segments are plausibly analyzed as underlying /p/ (e.g., McCawley 1968), especially since there is also a nonalternating $/ \mathrm{h} /$. Under this analysis, there should be many synchronic examples of NoP enforcement, namely, any form in which an alternating $[\mathrm{h}]$ appears.

As it turns out, however, the story of [p] is actually more complicated. It is noteworthy that [p] was almost never nativized even in the earliest Foreign borrowings; Irwin (2011:95-96) lists only loanword [p] as a possible outcome for source [p], and does not list source [p] as a possible origin for loanword [h]. Ito \& Mester (1999:97, note 42) do mention two sporadic and marginal examples of [p]-avoidance in loanwords: [ $\underline{\text { bateres] }}$ (now out of use) from Portuguese padre, and [heruri] in some mid-19th century documents referring to the US naval officer Matthew Perry. Still, the fact that such examples are so rare suggests that, despite the many $[\mathrm{h}] \sim[\mathrm{p}](\sim[\mathrm{b}])$ alternations in the Native and Sino-Japanese strata, speakers may not have had much of a productive restriction against [p] even before the Foreign items were borrowed.

One possible reason for this state of affairs is that there is a fifth lexical stratum, the Mimetic stratum (consisting of sound-symbolic items), which is similar to the Native stratum in many ways, and is sometimes analyzed as a subcase of the Native stratum (e.g., Irwin 2011:6). Unlike the Native stratum, however, the Mimetic stratum does allow singleton [p] (though only initially; Ito \& Mester 1995a), as in pittari 'right on, precisely' or pikapika 'bright, shiny' (reduplicated). We also note that, anecdotally, Japanese-speaking phonology students who encounter the 
traditional generative phonology analysis of $[\mathrm{h}] \sim[\mathrm{p}](\sim[\mathrm{b}])$ as /p/ often seem surprised. Thus, it may be that the $[\mathrm{h}] \sim[\mathrm{p}](\sim[\mathrm{b}])$ alternation is actually a case of phonologically conditioned, but not phonologically productive, allomorphy. Our nonce-loan nativization results support this view, since NoP is quite consistently the lowest ranked constraint across participants.

The rank of NoNT in the pooled results is also surprising - it is higher (and more variable) than expected. Not only does NoNT rank higher than NoP, as discussed above, but for many participants it is ranked as high as, or higher than, NoTT and/or NoDD.

One would expect NoNT to have a fairly low rank, because it is not productively active outside the Native stratum (Ito \& Mester 1999, 2003). It is even unclear whether NoNT is fully productive for Native forms, since the active morphological alternations showing its synchronic effects typically occur in verbs (examples in Ito \& Mester 1999:68, Ito, Mester \& Padgett 2001:57), while in nouns, the prohibition on voiceless obstruents after nasals may only have the status of a static distributional generalization. There are even a few NoNT violations within the Native stratum (K. Rice 1997), although Ito \& Mester (2003; Ito, Mester, \& Padgett 2001) argue that these NoNT-violating forms are typically syncopated variants of longer forms, so there may be output-output faithfulness to the unsyncopated variant at play.

And yet, although NoNT is generally dominated everywhere outside of the Native stratum (if not in the Native stratum as well), this constraint appears to have an exceptionally high rank for certain Sino-Japanese forms that unexpectedly participate in postnasal voicing (Ito \& Mester 2003; this pattern is seen in the example in (6c) above). This fact might be a precedent for speakers to assign an exceptionally high rank to NoNT for some or all nonce loans as well.

In summary, pooled results across all subjects provide evidence for a hierarchy of foreignness. However, the hierarchy differs somewhat from that proposed by Ito \& Mester (1999) on the basis of stratum-specific alternations. NoSI is ranked very high, as expected, indicating that [si] is very 'foreign'. NoP is ranked very low, which was somewhat unexpected; this indicates that $[p]$ is not so 'foreign'. Finally, not just NoTI and NoDD, but also NoNT, are variable between and within speakers. We conclude that, while there is a hierarchy of foreignness, existing stratum-specific alternations may not be the only factor determining this hierarchy. Furthermore, there are individual differences among participants with respect to the hierarchy of foreignness (as found by Smith \& Pinta 2015 for nonce-loanword nativization judgments in Guarani).

4.3. RESULTS: PRODUCTIVE CORE-PERIPHERY PHONOLOGY. We also analyzed our results for evidence of core-periphery structure as a productive part of the synchronic phonology. If coreperiphery structure is productive, the results should show two crucial patterns. First, participants should show impossible-nativization effects for each constraint pair: given a choice of nativizing only A or only B, participants should consistently prefer the same option each time A and B are compared. Second, each participant's preferences for the individual constraint pairs should form a coherent, transitive hierarchy: if $\mathrm{NoA} » \mathrm{NoB}$ and $\mathrm{NoB} » \mathrm{NoC}$, then we should find $\mathrm{NoA} » \mathrm{NoC}$. That is, a grammar with a productive core-periphery structure should not show 'foreignness reversals' in which property $\mathrm{A}$ is more foreign than $\mathrm{B}$, and $\mathrm{B}$ is more foreign than $\mathrm{C}$, but $\mathrm{C}$ is then judged as more foreign than A.

We found that participants were indeed likely to treat each constraint pair consistently. Specifically, we found that participants were more likely than expected to have uniform responses: constraint pairs (NoA, NoB) with $4 / 4$ responses supporting either NoA » NoB or $\mathrm{NoB} »$ NoA. Moreover, participants were less likely than expected to have constraint ties: 
constraint pairs (NoA, NoB) with 2/4 responses supporting NoA » NoB. Figure 3 shows, for each participant, how many of the 10 constraint pairs were ranked uniformly (dark blue) and how many were tied (light gray). While no participants had uniform rankings for all 10 constraint pairs, $21 / 40$ participants $(52.5 \%)$ had uniform rankings for 6-9 pairs (i.e., more than half of all pairs tested), and every participant had at least two uniform rankings. As for constraint ties, $29 / 40$ participants $(72.5 \%)$ had at most 2 ties, and $11 / 40$ participants $(27.5 \%)$ had no ties at all, while no participants had ties for more than 5 pairs.

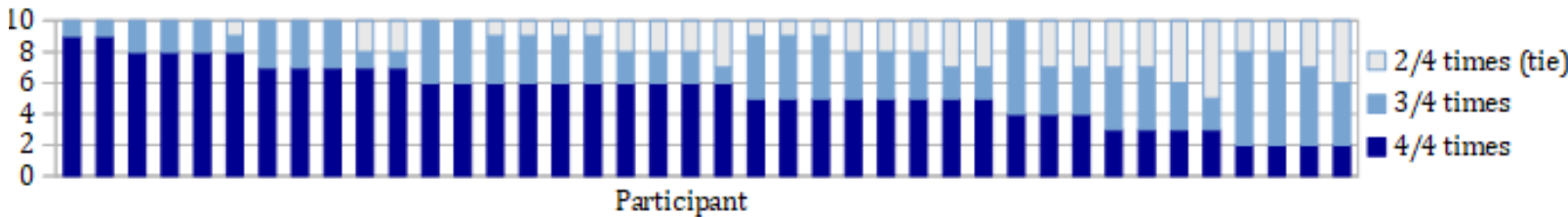

Figure 3: Proportion of constraint pairs with uniform (4/4), tied (2/4), and intermediate $(3 / 4)$ responses for each participant

In both cases, these results are strikingly different from what we would expect to see if participants were choosing responses randomly, that is, if the probability of responding NoA » $\mathrm{NoB}$ on each trial for all pairs (NoA, NoB) were $p=0.5$. Figure 4 compares the exact-binomial predicted distribution (light blue) to our observed distribution (dark blue) for uniform (4/4) rankings. If participants were responding at chance, most participants should have had 0-2 uniform rankings, and few to no participants should have had more than 4 uniform rankings.

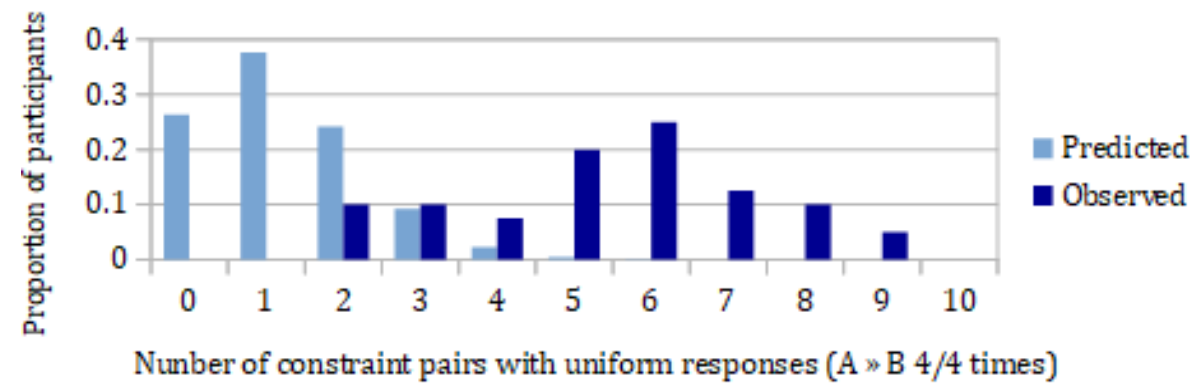

Figure 4: Predicted (exact binomial) vs. observed distribution of uniform rankings

Similarly, Figure 5 compares the exact-binomial predicted distribution (light blue) to our observed distribution (dark blue) for constraint ties (2/4 responses). If participants were responding at chance, many participants should have had 3 or 4 constraint ties, and very few should have had 1 or 0 ties.

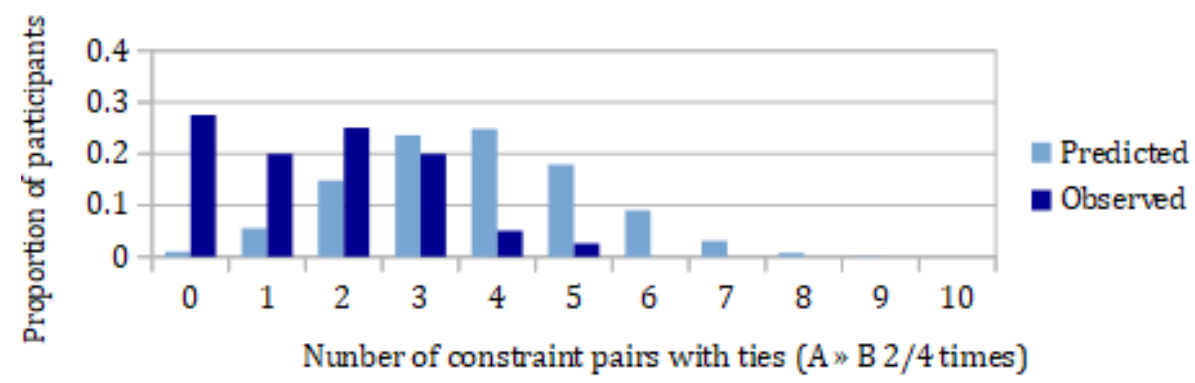

Figure 5: Predicted (exact binomial) vs. observed distribution of constraint ties

In summary, we found that participants treat each constraint pair more consistently than would be predicted by chance, with both a higher rate of uniform rankings and a lower rate of 
constraint ties than chance performance would predict. We conclude that participants do tend to show impossible-nativization effects.

For these impossible-nativization effects to provide evidence for productive core-periphery structure, however, the implicational relations between multiple pairs of constraints must also be transitive - for each participant, if $\mathrm{NoA} » \mathrm{NoB}$ and $\mathrm{NoB} » \mathrm{NoC}$, then we should find NoA » NoC as well. Our results show that some, but not all, participants actually have a transitive hierarchy.

Since each participant has four responses for a given constraint pair, we interpreted 4 or 3 'NoA » NoB' responses as evidence that NoA » NoB; 0 or 1 'NoA » NoB' responses as evidence that $\mathrm{NoB}$ » NoA; and 2 'NoA » NoB' responses as evidence that NoA=NoB (a tied or variable ranking). We then determined whether all 10 pairs' rankings were transitive for each participant. Rankings that included constraint ties were treated as partial orders (Anttilla 2007); for each tie $\mathrm{NoA}=\mathrm{NoB}$, two different expansions of the ranking were assessed, with NoA » $\mathrm{NoB}$ and $\mathrm{NoB}$ » NoA respectively, although this by-hand analysis procedure was only feasible with at most two pairs of tied constraints (see 7(d)).

(7) Proportion of participants with transitive, inconsistent, and multiply tied rankings

a. ranking is transitive (may include constraint ties) 17

b. ranking with 1-2 constraint ties; at least one expansion is transitive, 8 but at least one is inconsistent

c. ranking with 0-2 ties and no transitive expansion 4

d. ranking with more than two pairs of tied constraints (transitivity unknown) 11

As (7) shows, only about half the participants have a clearly transitive ranking.

4.4. DisCUSSION: PRODUCTIVE CORE-PERIPHERY PHONOLOGY. On the one hand, participants tended to give consistent responses for each constraint pair, indicating that they had preferences for particular nativizations over others. On the other hand, only about half the participants had pairwise preferences that can be unified into a transitive ranking.

We now consider whether there are any demographic or other participant-specific factors, as reported in the post-experiment questionnaire, that predict whether a given participant is more likely to have a transitive ranking. We found no effect of age, dialect region, education level, amount of English exposure, or self-reported reliance on audio vs. orthography in the nonce-loan nativization task. However, we did find a significant effect of participants' task-difficulty rating. We also found preliminary support for the view that participants who used more-implicit strategies were more likely to have transitive rankings.

The post-experiment questionnaire asked participants to rate the task as 'very easy', 'easy', 'very hard', or 'hard'. Participants were more likely to have transitive rankings if they rated the task as hard ('very hard' or 'hard') as opposed to easy ('easy' or 'very easy'), as shown in Figure 6 ; this difference was significant by Fisher's exact test $(p=0.041)$. 


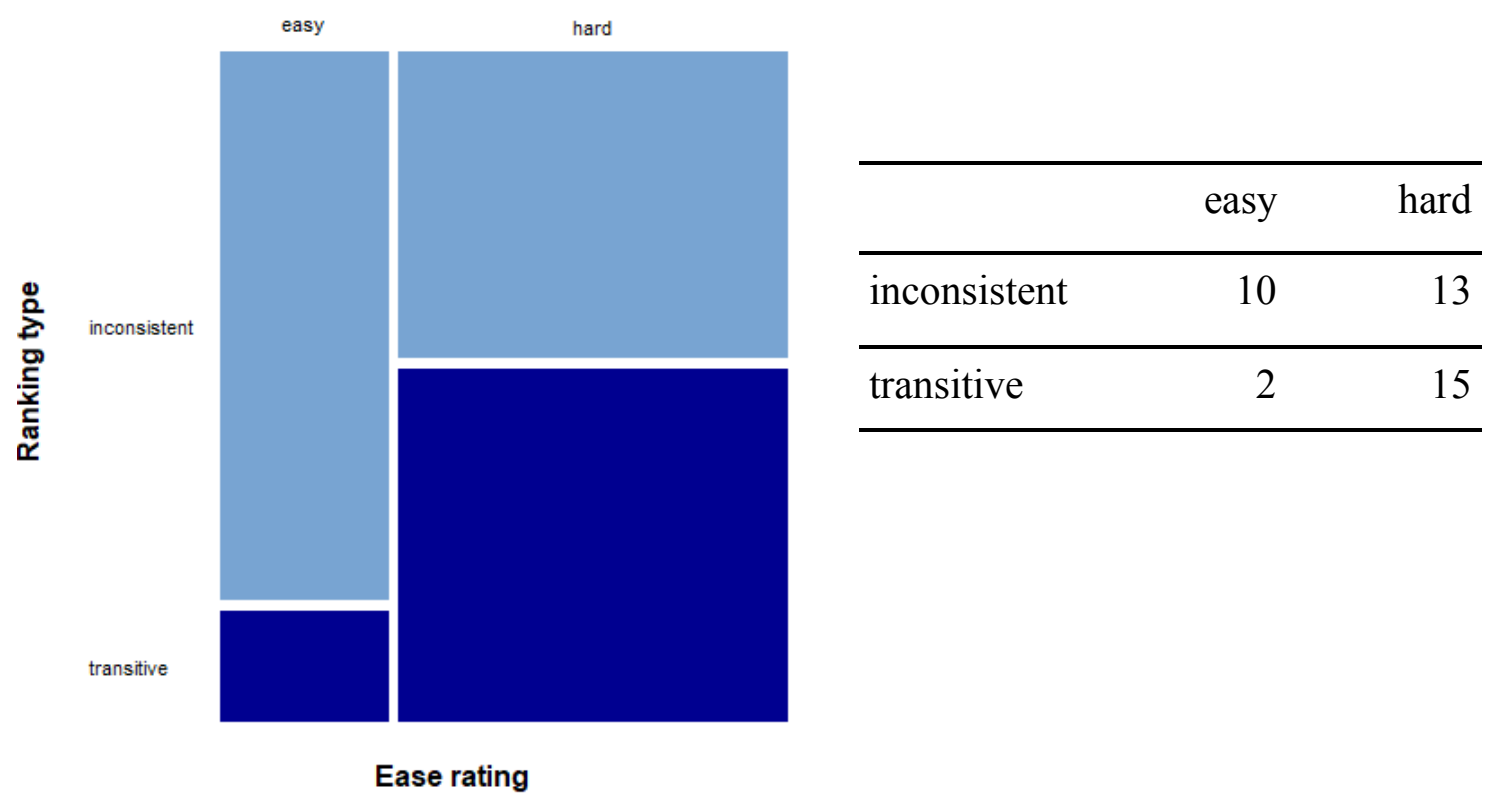

Figure 6: Ranking type by ease rating

It is difficult to conclude exactly why the ease rating is a predictor of transitive rankings, because participants might respond that the task is 'easy' or 'hard' for different reasons. For example, the task might seem 'hard' if participants feel unable to consciously access their criteria for preferring one nativization over another. Conversely, the task might seem 'hard' if participants are consciously using intentional problem-solving skills to choose a response. Distinctions like these are potentially very important; Moreton \& Pertsova (2017) show that response patterns can be qualitatively different for experiment participants who use implicit processing strategies (intuition) versus participants who use explicit processing strategies (problem-solving). Crucially, participants who respond on the basis of implicit strategies are more likely to be accessing their phonological grammar. But then how should we interpret the fact that an ease rating of 'hard' was more likely to predict a transitive ranking in this experiment - is it evidence that participants were using their phonological grammar (implicit strategies), or evidence that they were not using it (explicit strategies)?

To pursue this question, we explored possible effects of the (self-reported) use of particular implicit or explicit strategies in the experiment on the likelihood of participants' having a transitive ranking among all of their constraint preferences. Figure 7 shows the proportion of participants with transitive grammars in each of several 'strategy' categories; these categories were assigned on the basis of participants' answers to a free-response question about what strategies they felt they had been using in the experiment. While the number of participants in each category is small, there does seem to be preliminary evidence supporting the claim that participants using implicit strategies are more likely to have a transitive ranking. 


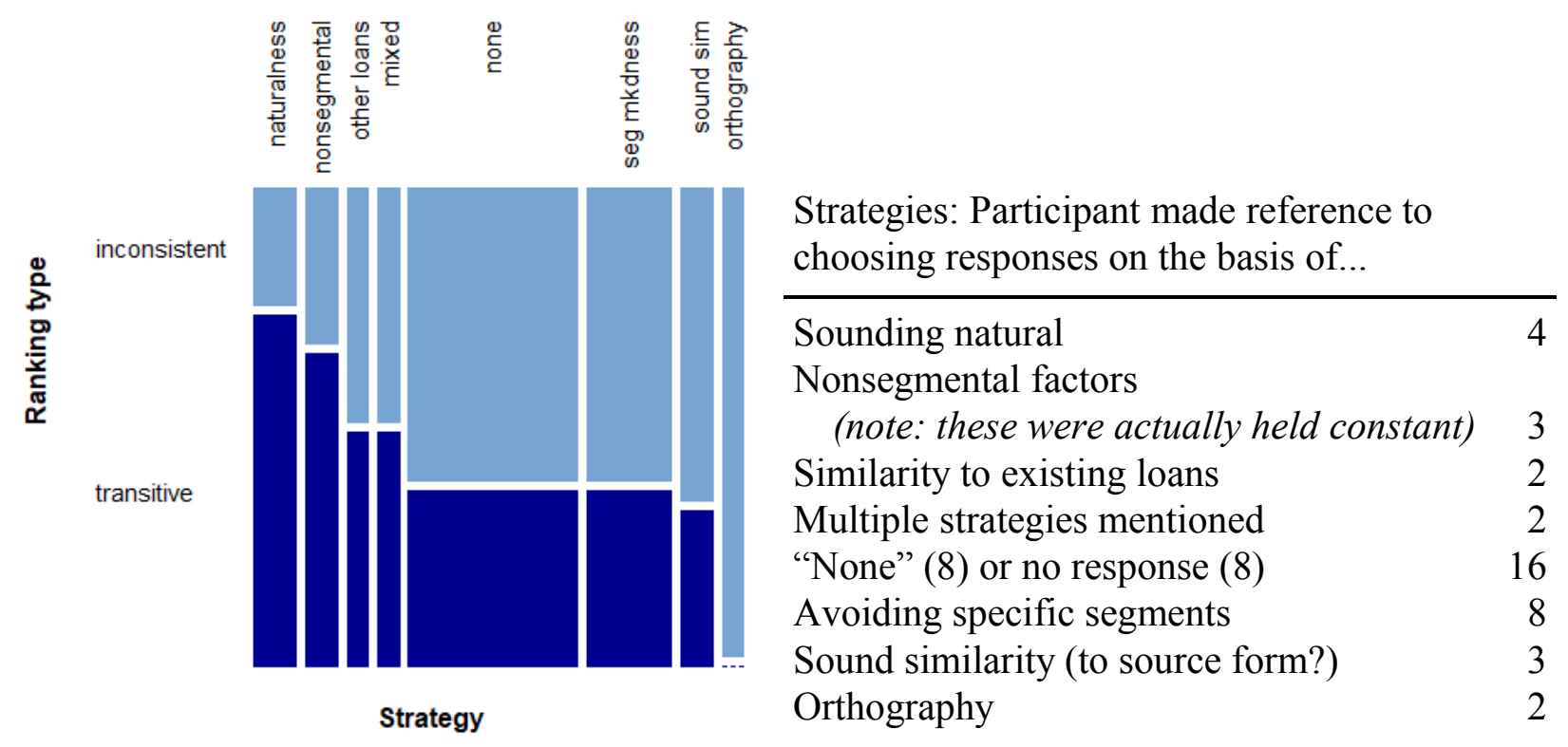

Figure 7: Ranking type by strategy

Strategies with high proportions of participants showing transitive hierarchies seem likely to be implicit. Three out of four participants who said they chose the response that sounded more natural have a transitive ranking. Two of the three participants who claimed to be choosing their responses on the basis of nonsegmental factors, such as pitch accent or stress, also have a transitive hierarchy; we classified this as an implicit strategy because such factors were held constant across the two response choices for a given item, and so participants who thought they were using these factors to make a choice could not actually have been doing so. Moreover, some of the strategies with low proportions of participants showing transitive hierarchies seem likely to be explicit. Of the two participants who reported using orthography-related factors to choose a response, neither had a transitive hierarchy. Of the eight participants who explicitly mentioned avoiding responses with particular segments, only three had a transitive hierarchy.

In summary, participants show impossible-nativization effects, in that responses to constraint pairs are largely consistent; that is, participants prefer certain nativizations over others. However, only about half of the participants had transitive preferences across all constraint pairs. This may have been because use of explicit strategies in the experiment masked participants' true grammars, although this question needs further study. At this point, we conclude that some, though not all, participants show evidence of productive core-periphery structure.

5. Conclusions and implications. Our pooled results support the existence of a hierarchy of foreignness in Japanese - some phonological structures are, overall, seen as more 'foreign' than others. However, we found that the existing stratum-specific alternations do not entirely predict the observed hierarchy, and in fact we found individual differences among participants.

Future work could further explore the differences between the expected and observed hierarchies. In particular, our results contribute to evidence that the productivity of certain alternations, such as those involving $[\mathrm{h}]$ and $[\mathrm{p}]$, should be reexamined. It would also be instructive to consider whether the type or token frequency of particular phonological structures 
in contemporary Japanese contributes to just how 'foreign' they seem to speakers. As for the individual differences, it might be interesting to consider what role is played by sociolinguistic factors, including attitudes toward lexical borrowing and particular non-Japanese languages, in the determination of which phonological structures feel more or less 'foreign' (see, e.g., Haugen 1950; Lovins 1975; Kenstowicz \& Sohn 2001).

Our results for individual participants indicate that some, though not all, Japanese speakers have productive core-periphery structure. Participants do largely show impossible-nativization effects in the form of consistent nativization preferences for pairs of 'non-native' properties. However, these pairwise nativization preferences appear to form a coherent transitive hierarchy for only about about half of the participants.

It would be interesting to explore further what leads to a transitive relationship among nativization preferences, and why some participants appear not to have such a relationship. As discussed above, it is possible that there are some participants who actually have a transitive ranking (a productive core-periphery phonology), but its effects are masked by the use of explicit problem-solving strategies in the experiment task. On the other hand, if it turns out that the apparent lack of transitivity for certain participants is really reflected in their phonological grammars, then this would have implications for the theoretical analysis of stratal phonology. For example, one possible source of conflicting preferences among multiple constraint pairs might be a grammar with a faithfulness ranking that changes across lexical strata, contra the metacondition on constraint rankings across strata known as Ranking Consistency (Ito \& Mester 1999). We will pursue such theoretical implications in future work.

\section{Appendix}

Example screen from experiment

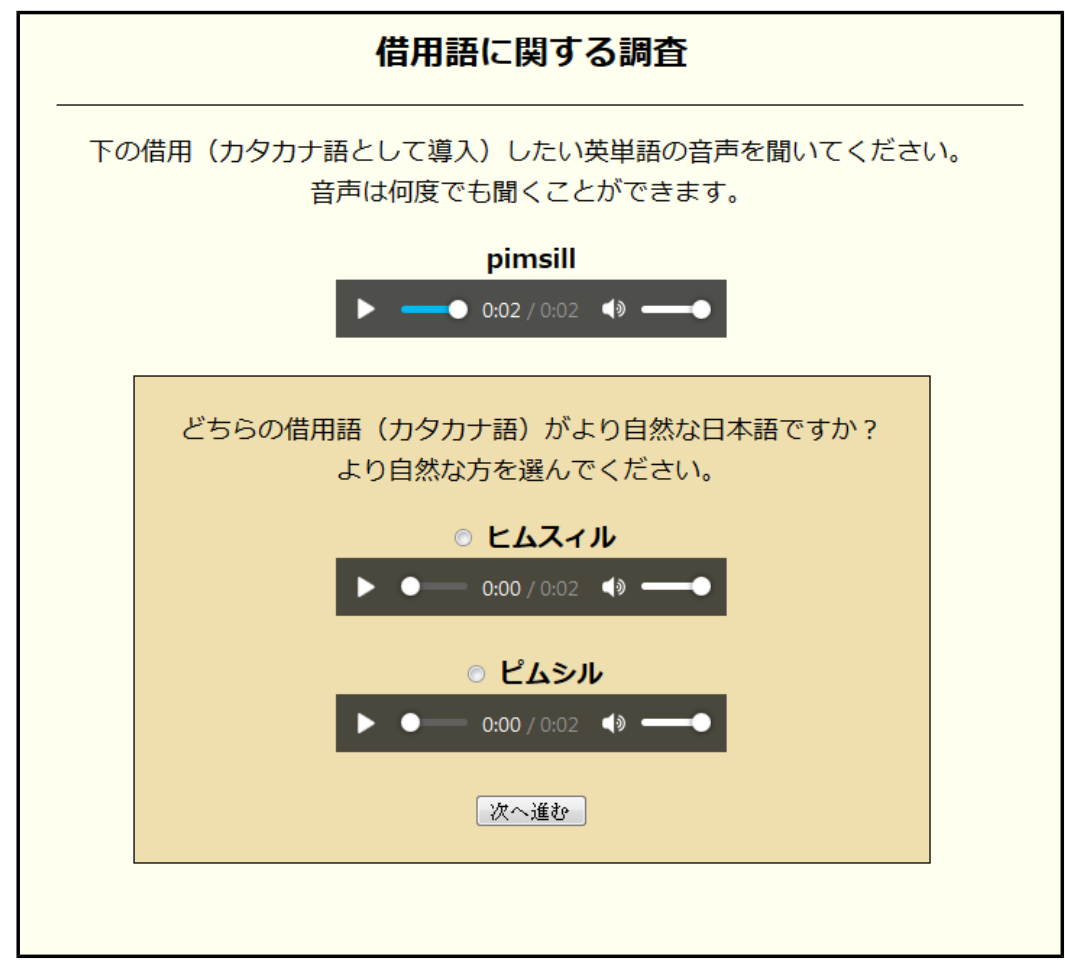


Example screen from experiment (translation)

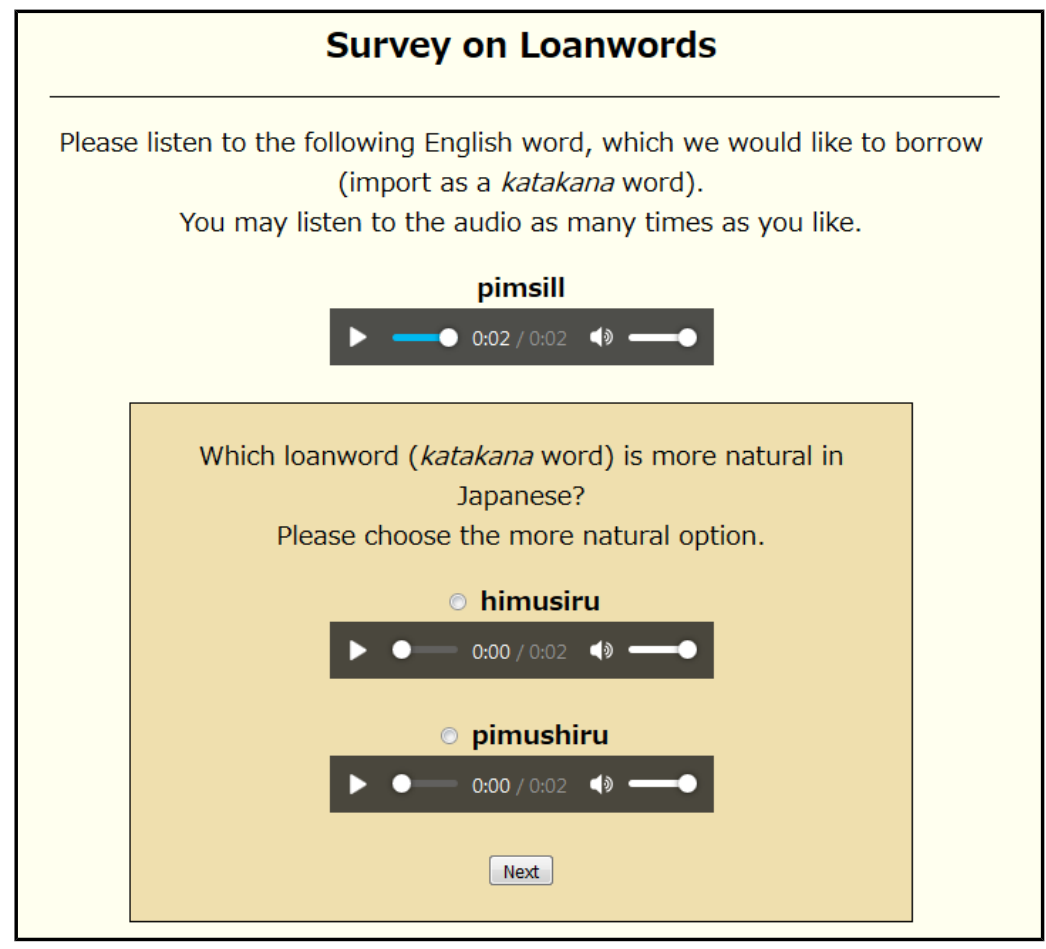

\section{References}

Anttila, Arto. 2007. Variation and optionality. In Paul de Lacy (ed.), The Cambridge handbook of phonology. 519-536. Cambridge: Cambridge University Press.

Chomsky, Noam \& Morris Halle. 1968. The sound pattern of English. New York: Harper and Row.

Haugen, Einar. 1950. The analysis of linguistic borrowing. Language 26(2). 210-231. https://doi.org/10.2307/410058.

Hayes, Bruce. 1999. Phonetically driven phonology: The role of Optimality Theory and inductive grounding. In Michael Darnell et al. (eds.), Formalism and functionalism in linguistics, vol. I. 243-285. Amsterdam: Benjamins.

Holden, Kyril. 1976. Assimilation rates of borrowings and phonological productivity. Language 52(1). 131-147. https://doi.org/10.2307/413213.

Hsu, Brian \& Karen Jesney. 2017. Loanword adaptation in Québec French: Evidence for weighted scalar constraints. West Coast Conference on Formal Linguistics (WCCFL) 34. 249-258.

Hsu, Brian \& Karen Jesney. 2018. Weighted scalar constraints capture the typology of loanword adaptation. Proceedings of the 2017 Annual Meeting on Phonology (AMP). https://doi.org/10.3765/amp.v5i0.4246.

Inkelas, Sharon \& Cheryl Zoll. 2007. Is grammar dependence real? A comparison between cophonological and indexed constraint approaches to morphologically conditioned phonology. Linguistics 45(1). 133-171. https://doi.org/10.1515/LING.2007.004.

Irwin, Mark. 2011. Loanwords in Japanese. Amsterdam: Benjamins. 
Ito, Junko \& Armin Mester. 1995a. The core-periphery structure of the lexicon and constraints on reranking. In Jill Beckman, Laura Walsh Dickey \& Suzanne Urbanczyk (eds.), Papers in Optimality Theory (UMOP 18). 181-209. Amherst: GLSA.

Ito, Junko \& Armin Mester. 1995b. Japanese phonology. In John Goldsmith (ed.), The handbook of phonological theory. 817-838. Cambridge, MA: Blackwell.

Ito, Junko \& Armin Mester. 1999. The structure of the phonological lexicon. In Natsuko Tsujimura (ed.), The handbook of Japanese linguistics. 62-100. Malden, MA: Blackwell.

Ito, Junko \& Armin Mester. 2001. Covert generalizations in Optimality Theory: The role of stratal faithfulness constraints. Studies in Phonetics, Phonology, and Morphology 7: 3-33.

Ito, Junko \& Armin Mester. 2003. Japanese morphophonemics: Markedness and word structure (Linguistic Inquiry Monograph Series 41). Cambridge, MA: MIT Press.

Ito, Junko, Armin Mester \& Jaye Padgett. 2001. Alternations and distributional patterns in Japanese phonology. Journal of the Phonetic Society of Japan 5(2). 54-60.

Kenstowicz, Michael \& Hyang-Sook Sohn. 2001. Accentual adaptations in North Kyungsang Korean. In Michael Kenstowicz (ed.), Ken Hale: A life in language. 239-270. Cambridge, MA: MIT Press.

Kiparsky, Paul. 1973. How abstract is phonology? In Osamu Fujimura (ed.), Three dimensions of linguistic theory. 5-56. Tokyo: Tokyo Institute for Advanced Studies of Language.

Lovins, Julie B. 1975. Loanwords and the phonological structure of Japanese. Bloomington: IULC.

McCawley, John D. 1968. The phonological component of a grammar of Japanese. The Hague: Mouton.

Moreton, Elliott \& Katya Pertsova. 2017. Implicit and explicit processes in phonotactic learning. Boston University Conference on Language Development (BUCLD) 40. 277-290.

Pater, Joe. 2001. Austronesian nasal substitution revisited. In Linda Lombardi (ed.), Segmental phonology in Optimality Theory: Constraints and representations. 159-182. Cambridge: Cambridge University Press.

Pinta, Justin. 2013. Lexical strata in loanword phonology: Spanish loans in Guarani. Chapel Hill, NC: University of North Carolina MA thesis.

Postal, Paul M. 1968. Aspects of phonological theory. New York: Harper and Row.

Saciuk, Bohdan. 1969. The stratal division of the lexicon. Papers in Linguistics 1(3). 464-532. https://doi.org/10.1080/08351816909389128.

Smith, Jennifer L. \& Justin Pinta. 2015. Experimental evidence for aggressive core-periphery phonology in Guarani. https://users.castle.unc.edu/ jlsmith/home/pdf/ smith\&pinta2015 mfm23 handout.pdf (January 24, 2019).

Rice, Curt. 2006. Norwegian stress and quantity: The implications of loanwords. Lingua 116(7): 1171-1194. https://doi.org/10.1016/j.lingua.2005.05.008.

Rice, Keren. 1997. Japanese NC clusters and the redundancy of postnasal voicing. Linguistic Inquiry 28(3). 541-551.

Vance, Timothy. 1987. An introduction to Japanese phonology. New York: SUNY Press. 